\title{
DESAFIOS PARA A EXTRAÇÃO SUSTENTÁVEL DE MINÉRIOS PORTADORES DE TERRAS RARAS
}

\author{
A. C. S. P. SOUZA, M. NASCIMENTO, E. C. GIESE* \\ Centro de Tecnologia Mineral, CETEM, Avenida Pedro Calmon 900, 21941-908, Rio de Janeiro, RJ \\ egiese@cetem.gov.br*
}

Artigo submetido 03/02/2019 e aceito 20/02/2019

DOI: $10.15628 /$ holos. 2019.8274

\section{RESUMO}

As Terras Raras são um grupo de elementos químicos que incluem todos os elementos do grupo dos lantanídeos, além do ítrio e escândio. Devido às suas propriedades químicas e físicas, as Terras Raras desempenham um papel essencial na indústria de produtos de alta tecnologia que tornam a disponibilidade destes elementos de suma importância para o avanço tecnológico, diretamente ligado à economia do país. As Terras Raras são encontradas em vários minerais, principalmente na monazita, na bastnasita, na xenotima e nas argilas de adsorção iônica. Devido à ocorrência do fenômeno de contração lantanídica, as Terras Raras possuem grande similaridade química e física, acarretando na dificuldade de separação e obtenção dos elementos lantanídeos na forma individual. Um dos grandes desafios da cadeia produtiva de Terras Raras é a busca por novos métodos de extração economicamente viáveis sem prejuízo do meio ambiente. Esta revisão bibliográfica pretende abordar os aspectos mineralógicos e químicos de diferentes minerais portadores de Terras Raras e discutir os desafios tecnológicos existentes nos processos de extração destes elementos, com foco no uso de tecnologias verdes para comporem a cadeia produtiva de Terras Raras.

PALAVRAS-CHAVE: Terras Raras, Minerais Portadores de Terras Raras, Lixiviação, Biolixiviação

\section{CHALLENGES FOR THE SUSTAINABLE EXTRACTION OF RARE EARTH ELEMENTS BEARING MINERALS}

\begin{abstract}
Rare Earth Elements are a group of chemical elements that include all elements of the group of lanthanides, in addition to yttrium and scandium. Due to their chemical and physical properties, Rare Earth Elements play an essential role in the high-tech product industry, making the availability of these elements extremely important for technological advancement, directly linked to the country's economy. Rare Earth Elements are found in several minerals, mainly monazite, bastnasite, xenotime and ionic adsorption clays. Due to the occurrence of the phenomenon of lanthanide contraction, the Rare Earths have great chemical and physical similarity, resulting in
\end{abstract}

the difficulty of separating and obtaining the lanthanide elements in the individual form. One of the great challenges of the production chain of Rare Earth Elements is the search for new methods of extraction economically viable without harm to the environment. This bibliographical review intends to approach the mineralogical and chemical aspects of different minerals bearing Rare Earth Elements and to discuss the technological challenges in the extraction processes of these elements, focusing on the use of green technologies to compose the production chain of Rare Earth Elements.

KEYWORDS: Rare Earth Elements, Rare Earth Elements Bearing Minerals, Leaching, Bioleaching 


\section{INTRODUÇÃO}

As Terras Raras (TRs) são encontradas em minerais metálicos estratégicos para o Brasil, as quais a produção e a demanda vêm se intensificando nas últimas décadas devido ao grande consumo pelos setores de alta tecnologia ( $W u$ et al., 2018). As TRs são um grupo de elementos químicos da série dos lantanídeos (do lantânio ( $L a, Z=57$ ) até o lutécio ( $L u, Z=71)$ ), acrescidos do escândio (Sc) e do ítrio (Y), que apresentam comportamentos químicos similares devido sua configuração eletrônica. Com exceção dos elementos $S c, Y, L a, Y b$ e $L u$, todas as TRs possuem a camada interna $4 \mathrm{f}$ incompleta, a qual é blindada pelas camadas mais externas. $O$ estado de oxidação trivalente é o mais comum e o mais estável termodinamicamente (Martins \& Isolani, 2005). Em geral, os elementos químicos de números atômicos inferiores aos do elemento gadolínio (Gd) são classificados como TRs leves, e os de números atômicos superiores aos do európio (Eu) são classificados como TRs pesadas. As TRs pesadas são mais escassas e difíceis de processar quando comparadas às TRs leves, o que as torna proporcionalmente mais valiosas (DNPM, 2014; McLellan et al., 2014).

Na natureza, as TRs não são encontradas como metais elementares nativos, presentes em minerais agregados à óxidos, fosfatos, silicatos, carbonatos e fluoretos, tendo uma concentração média de 10 a 300 ppm. Estima-se que existam cerca de mais de duzentas fases minerais que possuem, em sua composição, algum percentual de TRs, contudo apenas alguns destes apresentam concentração suficiente para justificar sua exploração. Dentre eles, podem ser citados a monazita, a xenotima, a bastnasita e as argilas de adsorção iônica (AAI) (McLellan et al., 2014; Zhang et al., 2015). Dentre os minerais portadores de TRs, a xenotima e as AAl são as principais fontes de TRs pesadas, enquanto a monazita e a bastnasita são conhecidas fontes de TRs leves (Santos \& Ribeiro, 2014; Ramalho et al., 2016.).

Apesar de serem chamadas TRs, o nome se contradiz com sua realidade, pois não são nem terras, muito menos raras. A nomenclatura surgiu no século 18 , quando estes elementos começaram ser descobertos e, por apresentarem um aspecto terroso, além da suposição equivocada de que seriam escassos na natureza, foram denominados raros (Lapido-Loureiro, 1993). Os elementos cério, lantânio e neodímio são mais abundantes do que os metais pesados cobalto, níquel e chumbo; já as TRs mais raras, túlio e lutécio, possuem ocorrência maior do que prata e metais do grupo da platina (Abrão, 1994).

Recentemente o Brasil passou a ser a 2- maior reserva mundial de TRs com a incorporação de expressivas reservas em Minas Gerais (MG) e Goiás (GO) detendo, ao final de 2012, 16\% do total mundial (Tabela 1). 
Tabela 1: Reservas naturais brasileiras de Terras Raras. (Fonte: Campos et al., 2014).

\begin{tabular}{llll}
\hline Local & Minério & $\begin{array}{l}\text { \% de Óxidos de } \\
\text { Terras Raras }\end{array}$ & $\begin{array}{l}\text { Reservas de } \\
\text { Terras Raras } \\
\text { (MT) }\end{array}$ \\
\hline Araxá-MG & Monazita & 3,25 & 26,69 \\
\hline Araxá-MG & Monazita & 3,99 & 0,9 \\
Araxá-MG & Monazita & N.D. & 8,0 \\
Catalão-GO & Monazita & 5,5 & 6,6 \\
Minaçu-GO & Argilas & 0,12 & 1,1 \\
Mata Azul-TO & Granitóides & N.D. & N.D. \\
Serra do Ramalho-BA & Similar à Baotou & $0,05-2,61$ & N.D. \\
Morro Seis Lagos-AM & (Mongólia) & & 43,5 \\
\hline
\end{tabular}

Atualmente, a China é responsável pela produção de $90 \%$ das matérias-primas que contém os elementos TRs e $85 \%$ dos óxidos de TRs (OTRs), o que equivaleu à produção de 122.220 toneladas de OTRs em 2016. O restante da produção global de TRs é distribuído entre Austrália (10\%), Malásia, Brasil, Índia, Rússia e Vietnã (Zhou et al., 2017). Espera-se que a taxa de crescimento anual da demanda global de TRs aumente em $5 \%$ até 2020 , devido à grande corrida pelo desenvolvimento de altas tecnologias que impulsionam o mercado de energia renovável (U.S. Department of Energy, 2010).

A Figura 1 ilustra a produção mundial de TRs ao longo dos anos. Até 1915, graças às areias do litoral do norte do Rio de Janeiro até o sul da Bahia, o Brasil foi o maior fornecedor mundial de monazita, mineral que contém as terras-raras, e até 1945 alternou a posição de maior produtor mundial com a Índia. Os Estados Unidos lideraram as exportações de TRs por 20 anos, no que ficou conhecido como a era "Mountain Pass", nome da principal mina do país, na Califórnia. Na década de 80, os Estados Unidos chegaram a produzir 20 mil toneladas de OTRs por ano. Nos anos 90, porém, com o domínio da China, a mineração de TRs foi abandonada pelos Estados Unidos e apenas a empresa Molycorp seguia produzindo óxidos de neodímio, praseodímio e lantânio, a partir dos estoques de Mountain Pass, para processamento por outras empresas fora do território norte-americano. Após o choque de preços imposto pela China em 2011, o cenário é de retomada da produção no Brasil e em todo o mundo (Senado Federal, 2013). 


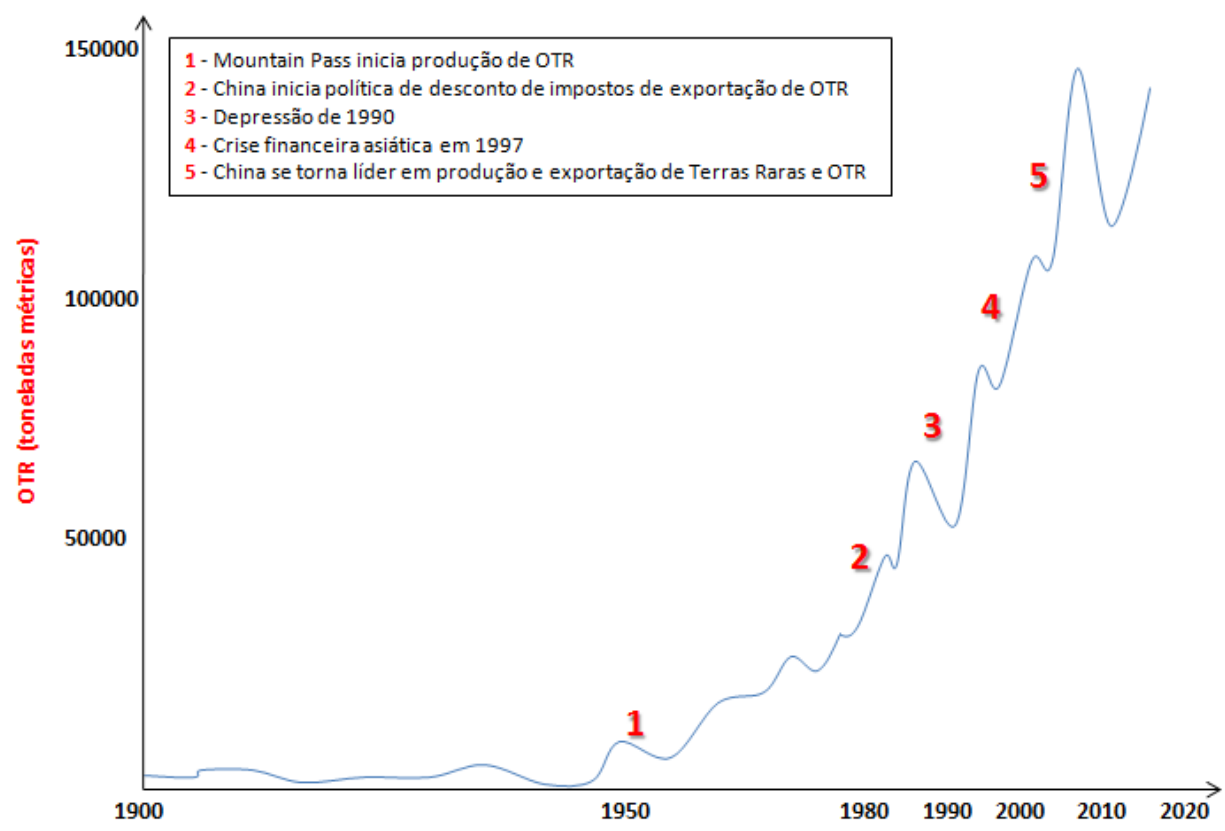

Figura 1: Produção mundial de Terras Raras ao longo dos anos. (Fonte: Zhou et al., 2017)

Devido sua alta similaridade química, a separação e purificação das TRs individuais apresentam dificuldades, além de custo elevado. Em geral, o processo de extração das TRs passa por etapas iniciais de beneficiamento físico, seguido de etapas de processamento químico (Kim \& Osseo-Asare, 2012). Entre as diversas metodologias convencionais de separação das TRs, a hidrometalurgia apresenta operações unitárias de extração destes elementos na qual a principal etapa de envolve reações de dissolução do mineral-minério em meio aquoso. A pirometalurgia, por sua vez, apesar de ser empregada industrialmente, envolve o emprego de altas temperaturas, com um consumo de energia consideravelmente alta (Haque et al., 2014).

Uma das técnicas de extração mais utilizada consiste no processo de lixiviação seguido da extração por solvente. A lixiviação extrai a substância(s) desejada(s) de uma matriz sólida através da dissolução por um agente lixiviante, que pode ser um ácido, uma base ou um sal, transferindo os metais presentes no minério para a solução, esta denominada licor ou lixiviado (Takahashi, 2008). Na técnica de extração por solvente, o licor de lixiviação que contém o metal de interesse é colocado em contato com um solvente orgânico, sendo os dois imiscíveis, distribuindo-se assim o metal nas duas fases. A transferência do metal para a fase desejada depende da natureza do solvente e das condições de extração escolhidas (Vera, 2015).

Para os minérios de baixo teor, esses métodos convencionais geralmente exigem uma alta demanda de energia para gerar altas temperaturas ou dispendem do uso de maior quantidade de reagentes químicos, o que aumenta o custo do processo e a geração de resíduos (Barmettler et al., 2016). Assim, há uma necessidade de se buscar novas metodologias alternativas de extração de TRs a partir destes minerais. 


\section{TERRAS RARAS}

\subsection{Propriedades químicas e físicas das Terras Raras}

Os lantanídeos podem ser classificados em: - leves (57-60): lantânio (La), cério (Ce), praseodímio ( $\mathrm{Pr}$ ) e neodímio ( $\mathrm{Nd}$ ); - médios (61-64): promécio (Pm), samário ( $\mathrm{Sm})$, európio (Eu) e gadolínio (Gd); - pesados (65-71) : térbio (Tb), disprósio (Dy), hólmio (Ho), érbio (Er), túlio (Tm), itérbio (Yb) e lutécio (Lu). O arranjo dos elétrons ao redor dos núcleos das diferentes TRs é um fator determinante das propriedades destes elementos. As configurações eletrônicas da série dos lantanídeos envolvem o preenchimento regular da camada interna $4 \mathrm{f}$, enquanto a camada externa $5 d$ permanece vazia, no processo de Ce para $Y$, mas com exceção do $\mathrm{Gd}$ que tem um elétron na camada $5 \mathrm{~d}$. O La e o Lu também possuem um elétron na camada $5 \mathrm{~d}$. Em seu estado oxidado, os elementos não possuem um elétron na camada externa $5 d$, onde qualquer mudança no número de elétrons é refletido no nível $4 \mathrm{f}$ interno (Jones, Wall \& Williams, 1996).

A alta similaridade das TRs dificulta a separação dos lantanídeos para a obtenção dos elementos individuais. Eles apresentam o fenômeno conhecido como contração lantanídica, onde se observa a diminuição progressiva dos raios atômicos e iônicos com o aumento do número atômico (Sousa Filho \& Serra; 2014). A contração lantanídica é causada por uma blindagem imperfeita de um elétron por outro no mesmo orbital, de modo que a adição de um elétron $4 f$ resulta no aumento da carga efetiva nuclear, resultando na redução em tamanho do volume da configuração inteira 4f. Assim, o La apresenta o maior raio iônico, enquanto o Lu apresenta o menor raio iônico (Abrão, 1994).

As similaridades dos raios e estados de oxidação das TRs permitem a substituição de um elemento por outro em várias redes cristalinas, o que explica a sua ampla dispersão na crosta terrestre e as múltiplas ocorrências em um único mineral. As diferenças químicas e físicas existentes entre as TRs são causadas pelas pequenas diferenças no raio iônico e geralmente resultam na segregação de TRs em depósitos enriquecidos em lantanídeos leves ou lantanídeos pesados (Castor \& Hedrick, 2006).

O tamanho do raio iônico também interfere diretamente na basicidade das TRs, onde o maior raio iônico tende a perder ânions ou elétrons, tornando-os menos atraídos e, conseqüentemente, mais básicos. Dessa forma, a basicidade das TRs é decrescente do La ao Lu, com o Y e o Sc mostrando também baixos valores. Os procedimentos extrativos metalúrgicos de separação desses elementos também são interferidos pela basicidade, a qual diminui com o aumento do estado de oxidação das espécies em questão. Este fator determina as possibilidades hidrometalúrgicas de hidrólise e solubilidade dos cátions, de cristalizações e precipitações fracionadas, trocas iônicas e oxidação seletiva (Gupta \& Krishnamurthy, 1995).

As propriedades nucleares definem alguns quesitos de predominância das TRs, onde os elementos de número atômico par são mais abundantes que os de número atômico ímpar. O Ce é o lantanídeo mais abundante na crosta terrestre, o Y se aproxima do La, e o Nd é mais abundante que $\mathrm{Pm}$. Devido às transições $\mathrm{f}$ - $\mathrm{f}$, vários lantanídeos apresentam íons coloridos, dando a existência de fenômenos de luminescência ou fluorescência de certos íons (Abrão, 1994). O promécio é uma exceção, pois não ocorre naturalmente, sendo recuperado dos subprodutos da fissão do urânio (Serra et al., 2015). 
As TRs são muito eletropositivas e seus compostos são geralmente iônicos. Do ponto de vista mineralógico, estes compostos são óxidos, haletos, carbonatos, fosfatos e silicatos, com algumas adições, como borato e arseniato. Seus raios iônicos são relativamente grandes e, portanto, as reações de substituição geralmente envolvem os grandes cátions, como o cálcio ou o estrôncio, embora seja necessário algum balanceamento de carga adicional (Jones, Wall \& Williams, 1996).

As TRs são enriquecidas na ferrugem da Terra, conhecidas como elementos litófilos, o que naturalmente ocorrem juntos porque todos são trivalentes, com exceção do Eu no estado 2+ e do Ce no estado 4+ (Castor \& Hedrick, 2006). A proporção dos diferentes estados de oxidação do Eu ou Ce em qualquer sistema dependerá das condições de temperatura, pressão, composição e redox (Jones, Wall \& Williams, 1996). Em termos de reatividade, os metais de TRs são rapidamente oxidados quando em altas temperaturas e na presença de umidade (Antoniassi, 2017).

\subsection{Terras Raras no Brasil}

No Brasil, a busca pelas TRs teve início por volta de 1885, com a retirada da monazita das praias de prado, na Bahia. Com o pretexto de que os navios não poderiam voltar vazios para a Europa ou aos Estados Unidos, as areias eram usadas como lastro de navios, o que se estima que entre 1885 e 1890, John Gordon, engenheiro da firma norte-americana, tenha embarcado cerca de 15000 toneladas de monazita brasileira. Os principais destinos da monazita brasileira eram a Áustria e a Alemanha, onde Carl Auer inventou as camisas para a iluminação a gás, acarretando na primeira aplicação comercial das TRs. Em tais condições, o Brasil foi o líder do fornecimento mundial de monazita (Sousa Filho \& Serra; 2014).

No final da década de 1940 teve-se início a produção de TRs no Brasil, onde a primogênita da produção foi a Usina Santo Amaro (USAM), pertencente à ORQUIMA - Indústrias Químicas Reunidas S/A, localizadas na cidade de São Paulo. Em 1960 foi observada na monazita a presença de urânio e tório, o que acarretou a estatização da SULBA, sendo suas atividades assumidas pela Comissão Nacional de Energia Nuclear - CNEN. Nesse momento, a CNEN assumiu também a unidade de tratamento da monazita (TQM) da ORQUIMA. Em 2005, em nível mundial, o tratamento da monazita encontrou-se dentro dos melhores padrões tecnológicos, apresentando os melhores resultados levando a colocação no mercado de novos produtos (Rosental, 2005).

Em 1989, foi criada a Câmara Setorial das Terras Raras, entidade que reunia empresas institutos e centros de pesquisas para discussão de aspectos técnicos e econômicos da produção de TRs. Em 1991, a Nuclemon Mineroquímica, única processadora de minérios portadores de TRs no Brasil, desde a mina até os produtos fracionados, interrompe suas atividades. Como já se delineava ao final da década de 80 , os anos 90 deveriam caracterizar-se principalmente pelo desenvolvimento das tecnologias de aplicação de TRs nos EUA, Europa, Japão e China. Para o Brasil, definiram-se perspectivas da conquista da tecnologia e implementação de unidades de fracionamento de TRs por extração por solventes e troca iônica, com a ampliação das ainda limitadas pesquisas em aplicação (Loureiro \& Santos, 2013).

Em 2013, o CETEM retomou os estudos sobre TRs através do desenvolvimento do projeto PROTERRARAS, buscando o maior aperfeiçoamento de mão de obra qualificada com 
desenvolvimento de competência tecnológica, visto aos desafios do país na implantação de uma cadeia produtiva de TRs (TCG, 2013). Atualmente as principais entidades que se envolvem em pesquisa e produção de TRs no Brasil são: DNPM (Departamento Nacional de Produção Mineral, hoje Agência Nacional de Mineração); CETEM (Centro de Tecnologia Mineral); IPEN (Instituto de Pesquisas Energéticas e Nucleares); CBMM (Companhia Brasileira de Metalurgia e Mineração); e universidades que atuam na pesquisa científica e tecnológica (Loureiro, 1994; Sousa Filho \& Serra, 2014).

Dentre os projetos atuais de TRs no Brasil, cabe destacar o pioneirismo e vanguarda da CBMM, que já conta com um projeto piloto em operação. Além de ocorrências e reservas já identificadas, podemos citar a possibilidade de identificar elementos de TRs como subprodutos em diversos projetos já em produção, através de reciclagem, reaproveitamento de barragens de rejeito e de pilhas de estéril seletivas. Os principais projetos brasileiros em andamento são: CBMM (Araxá/MG); Serra Verde (Minaçu/GO); Pitinga/Mineração Taboca (Presidente Figueiredo/AM); Anglo American (Catalão/GO); Primestar Mineração (Projeto Morro do Ferro/MG); MbAC (ativos minerários em Araxá/MG); Placers (areia monazítica - diversos no Brasil); Seis Lagos (SGB/CPRM); Rejeitos da INB em Caldas/MG e Mineração Mata Azul (Tocantins) (Heider, 2018).

\subsection{Aplicações das Terras Raras}

A demanda pelas TRs vem se intensificando devido ao crescimento da demanda dos metais e óxidos de grande pureza para investimentos em alta tecnologia. A primeira aplicação de TRs ocorreu em 1883 com o desenvolvimento da iluminação à gás, onde as camisas dos lampiões eram compostas de óxidos e zircônio. Atualmente as TRs são aplicadas em produtos industriais de alta tecnologia, como agentes catalíticos, metalurgia, na eletrônica, entre outros (Loureiro, 1994). Algumas aplicações de tais elementos encontram-se ilustrados de forma resumida na Figura 2.

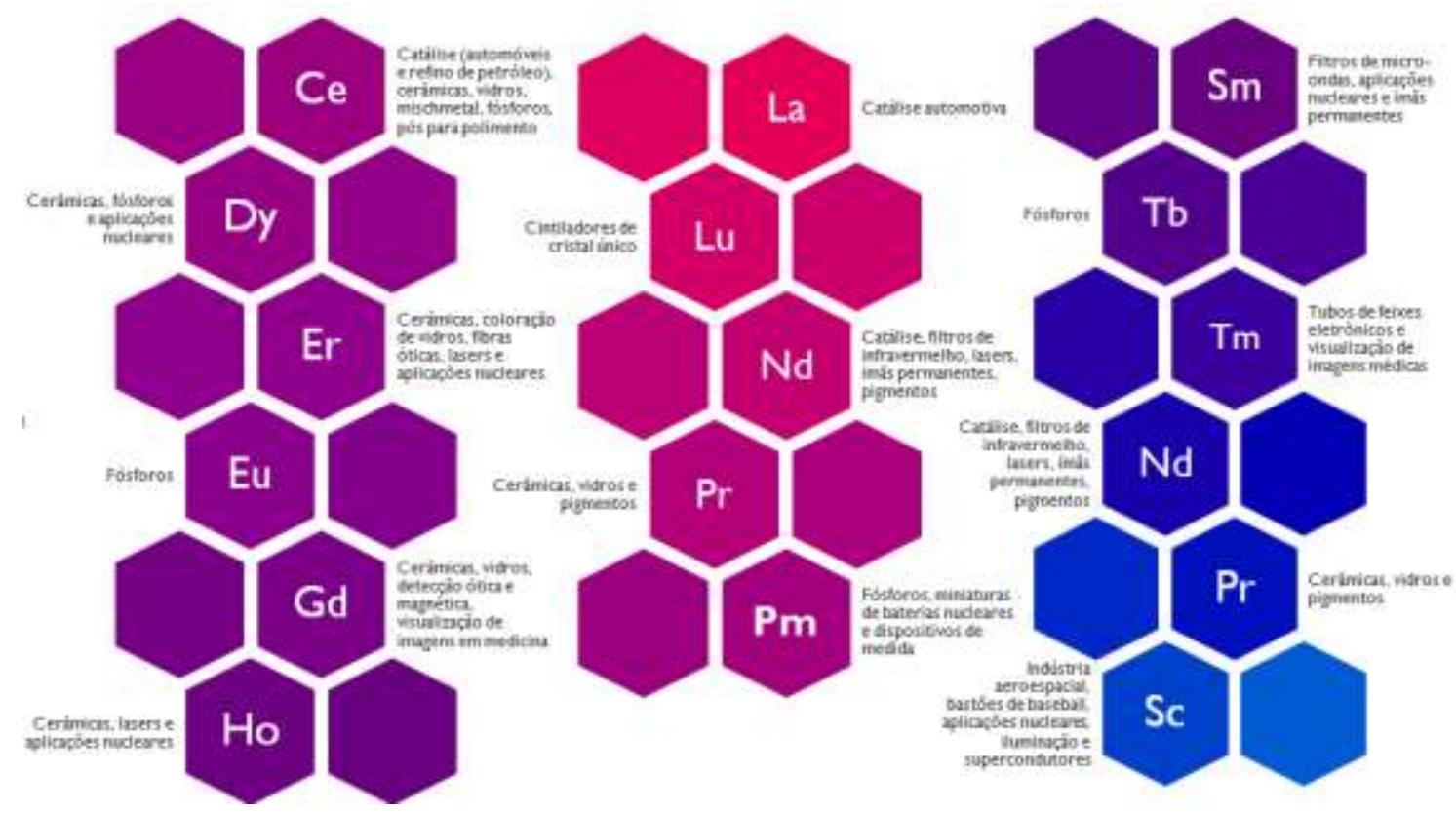

Figura 2: Campos de aplicações dos elementos Terras Raras, em ordem alfabética (Autoria Própria). 
No entanto, a partir de 2010, a China, portadora dos maiores recursos mundiais em TRs, impôs restrições comerciais, limitando dessa forma suas exportações ao máximo de 35 mil toneladas anuais de OTRs, levando o governo e a indústria mineral mundial a buscar outras fontes para suprir seu consumo (Antoniassi, 2017).

Atualmente, as TRs são cada vez mais usadas nas indústrias ligadas à energia, ocorrendo uma busca incessante por esses elementos. Com uma finalidade ambiental comprovada, as consideradas 'indústrias verdes' buscam as TRs para o desenvolvimento de carros híbridos, motores elétricos das turbinas eólicas, tornando as TRs um importante bem material estratégico, onde haverá um aumento de consumo (Loureiro \& Santos, 2013).

Devido esta situação, têm sido implementados, tanto por órgãos governamentais quanto por mineradoras, estudos de caracterização tecnológica para o entendimento das características intrínsecas dos minerais de interesse, buscando assim aprofundar seus conhecimentos sobre os recursos minerais associados os TRs (Antoniassi, 2017).

\subsection{Minerais portadores de Terras Raras}

Segundo Abrão (1994), a classificação dos minerais presentes em rochas é realizada de acordo com a quantidade de TRs presentes. Podem ser classificados em: minerais comuns em rochas, onde as TRs estão presentes em concentrações mínimas; minerais que contenham TRs, porém em baixas concentrações (mais de 200 espécies minerais); ou minerais em que as TRs são essenciais, conhecidos como "minerais de Terras Raras".

As TRs não ocorrem como metais elementares nativos na natureza, apenas como parte da química do mineral hospedeiro. Com isso, os minerais devem ser quebrados quimicamente para que ocorra a recuperação de TRs (Gupta \& Krishnamurthy, 2005). As TRs leves são encontradas nos minerais de bastnasita e monazita, enquanto as TRs pesadas são encontradas na xenotima e nas AAI (Antoniassi, 2017).

O mais abundante dos minerais portadores de TRs é a bastnasita, mineral de carbonato encontrado na veia de depósitos, zonas metamórficas de contato e pegmatitos. Já os minerais xenotima e monazita são minerais de fosfatos que podem ocorrer juntos, mas cristalizam em diferentes regimes de temperatura e pressão de um ambiente ígneo similar (Usepa, 2012).

O processo químico conhecido como intemperismo é um mecanismo que altera originalmente as rochas portadoras de TRs, atuando na solubilização de minerais primários como carbonato e apatita, liberando $\mathrm{TRs}, \mathrm{CO}_{3}{ }^{2-}$ e $\mathrm{PO}_{4}{ }^{3-}$ para a formação de monazita secundária ou bastnasita secundária (Mariano, 1989). Na Figura 3 estão ilustrados alguns minerais portadores de TRs e suas estruturas. 


\begin{tabular}{|c|c|}
\hline Mineral & Fórmula Química \\
\hline Alanita & $(\mathrm{Ca}, \mathrm{R})_{2}(\mathrm{Al}, \mathrm{Fe}, \mathrm{Ma}, \mathrm{Mg})_{3}(\mathrm{SiO})_{3}(\mathrm{OH})$ \\
\hline Apatita & $(\mathrm{Ca}, \mathrm{R})_{5}\left(\mathrm{P}, \mathrm{Si}\left(\mathrm{O}_{4}\right)_{3}(\mathrm{O}, \mathrm{F})\right.$ \\
\hline Bastnaesita & $\mathrm{RFCO}_{3}$ \\
\hline Branerita & $\mathrm{R}(\mathrm{Ti}, \mathrm{Si}) \mathrm{O}$ \\
\hline Cerita & $\mathrm{CaRSi}_{3} \mathrm{O}_{13}$ \\
\hline Euxenita & $(\mathrm{Ca}, \mathrm{R})(\mathrm{Nb}, \mathrm{Ta}, \mathrm{Ti}) \mathrm{O}_{6}$ \\
\hline Fergusonita & $(\mathrm{R}, \mathrm{Ca})(\mathrm{Nb}, \mathrm{Ta}, \mathrm{Ti}) \mathrm{O}_{4}$ \\
\hline Fluorocerita & $\mathrm{RF}_{3}$ \\
\hline Fluorita & $\mathrm{CaF}_{2}$ \\
\hline Gadolinita & $\mathrm{Be}_{2} \mathrm{FeR}_{2} \mathrm{Si}_{2} \mathrm{O}_{10}$ \\
\hline Loparita & $(\mathrm{Ca}, \mathrm{R})(\mathrm{Ti}, \mathrm{Nb}) \mathrm{O}$ \\
\hline Monazita & $(\mathrm{R}, \mathrm{Th}) \mathrm{PO}_{4}$ \\
\hline Perovskita & $\mathrm{CaTiO}_{4}$ \\
\hline Pirocloro & $(\mathrm{NaCaR})_{2} \mathrm{Nb}_{2} \mathrm{O}_{6} \mathrm{~F}$ \\
\hline Samarskita & $(\mathrm{R}, \mathrm{Ca})(\mathrm{Nb}, \mathrm{Ta}, \mathrm{Ti})_{2} \mathrm{O}_{6}$ \\
\hline Xenotima & $\mathrm{RPO}_{4}$ \\
\hline Zircão & $\mathrm{ZrSiO}_{2}$ \\
\hline
\end{tabular}

Figura 3: Exemplos de minerais que contém Terras Raras em sua estrutura (Fonte: Abrão, 1994).

\subsubsection{MONAZITA}

A monazita é um ortofosfato com predominância de TRs leves, monoclínico, com densidade entre 4,6 e 5,4, dureza entre 5,0 e 5,5, e apresenta lustro resinoso. Sua coloração geralmente é marrom, variando de amarela a avermelhada, podendo também ser esverdeada ou quase branca (Abrão, 1994). De acordo com Usepa (2012), a predominância de TRs leves é devido a menor temperatura de cristalização.

Apresenta fórmula química ( $\mathrm{Ce}, \mathrm{La}, \mathrm{Nd}, \mathrm{Th}) \mathrm{PO}_{4}$, com aproximadamente $70 \%$ de OTRs. Em sua composição pode encontrar-se elementos radioativos, cerca de $0,1 \%-30 \%$ de tório, e até 1,5\% de urânio, sendo esses elementos responsáveis por conferir propriedades elétricas, magnéticas e catalíticas a alguns óxidos. (Abrão, 1994). Além desses elementos, ocorrem quantidades moderadas de ferro, alumínio, cálcio, magnésio, sílica, titânio e zircônio (Zini, 2010).

O primeiro mineral portador de TRs a ser explorado industrialmente foi a monazita. Seu nome é derivado do grego monazein, que significa "estar sozinho", observado através de suas características de cristais isolados e por ser bastante raro no período da sua descoberta, dando uma alusão à raridade do mineral (Voncken, 2016). Entre as possíveis aplicações tecnológicas 
pode-se citar a produção de várias ligas (Metalurgia), de catalisadores (petróleo e gás), a componentes eletrônicos (tecnologia da informação), entre outros (Loureiro, 1994).

No processamento físico, a concentração de minerais pesados provém de uma combinação de métodos, envolvendo separações densitárias, eletrostática e, magnéticas, dependendo da assembleia mineralógica dos minerais a serem aproveitados (Viera \& Lins, 1997). A monazita é produzida predominantemente como subproduto da mineração de areias com minerais pesados (depósitos de placers), de onde são também comumente explorados minerais de titânio e zircônio. Devido à monazita apresentar certo grau de magnetismo, os minerais condutores são posteriormente separados por meios magnéticos (Antoniassi, 2017).

\subsubsection{BASTNASITA}

A bastnasita é um fluorcarbonato de TRs cuja composição é semelhante à da monazita, com predominância de cério, lantânio, praseodímio, neodímio, contendo cerca de $75 \%$ de OTRs em sua composição. Apresenta fórmula química $\mathrm{Ce}\left(\mathrm{CO}_{3}\right) \mathrm{F}$, onde a cor é geralmente castanho claro, podendo variar para amarela, amarela avermelhada e castanho avermelhado. Tem dureza aproximada de 4,5 e densidade $5 \mathrm{~g} / \mathrm{cm}^{3}$ (Abrão, 1994).

Conforme citado por Voncken (2016), a bastnasita foi descrita pela primeira vez pelo químico sueco Wilhelm Hisinger como "base-fluor-cério", da mina de Bästnas, perto de Riddarhyttan, Västmanland, Suécia. É outro mineral de importância de TRs, contendo principalmente TRs leves, com baixas proporções de TRs pesadas. É um mineral substituinte da monazita por não conter concentrações de elementos radioativos. A bastnasita ocorre em uma variedade de rochas ígneas, como carbonatitos, depósitos em veios, rochas metamórficas de contato e pegmatitos (Gupta \& Krishnamurthy, 2005; Vonken, 2016).

\subsubsection{XENOTIMA}

A xenotima é um fosfato mineral de ítrio e TRs pesadas, tetragonal e densidade entre 4,4$5,1 \mathrm{~g} / \mathrm{cm}^{3}$, dureza de 4 a 5 e brilho vítreo (Abrão, 1994). Apresenta em sua composição $67 \%$ de OTRs, sendo predominante os elementos pesados ( $\mathrm{Y}, \mathrm{Tb}, \mathrm{Dy}, \mathrm{Ho}, \mathrm{Er}, \mathrm{Tm}, \mathrm{Yb}$ e Lu), mas também sendo encontrado TRs leves em proporções menores que as encontradas na monazita e na bastnasita. A xenotima pode ser encontrada associada à monazita em concentrações variando de 0,5-5,0\% de monazita. Apresenta fórmula YPO4 e entre suas mais importantes propriedades físicas, pode-se mencionar que é mais fortemente magnética que a monazita, fato que permite sua separação por métodos magnéticos (Santos \& Ribeiro, 2014).

A xenotima foi mencionada pela primeira vez por Berzelius em um espécime de Hidra, Flekkefjord, Vest-Agder, Noruega, conforme citado por Voncken (2016). O nome é derivado do grego xenos - "estrangeiro" e do tempo - "honra". A xenotima é um mineral acessório em pegmatitos graníticos e outras rochas ígneas (não básicas), e também se concentra em placers e areias minerais pesadas. No entanto, esses depósitos não são generalizados. Na Tabela 2 são apresentados exemplos de composições típicas de monazita, xenotima e bastnasita. 
Tabela 2: Exemplos de composições típicas de monazita, xenotima e bastnasita.

\begin{tabular}{llll}
\hline Elementos & Monazita-Ce & Monazita-La & Xenotima-Y \\
\hline $\mathrm{La}_{2} \mathrm{O}_{3}$ & 16,95 & 33,95 & - \\
$\mathrm{Ce}_{2} \mathrm{O}_{3}$ & 34,16 & 17,10 & - \\
$\mathrm{ThO}_{2}$ & 5,50 & 5,50 & - \\
$\mathrm{P}_{2} \mathrm{O}_{5}$ & 29,55 & 29,58 & 38,60 \\
$\mathrm{Nd}_{2} \mathrm{O}_{3}$ & 14,01 & 14,03 & - \\
$\mathrm{Y}_{2} \mathrm{O}_{3}$ & - & - & 61,40 \\
$\mathrm{CO}_{2}$ & - & - & - \\
$\mathbf{F}$ & - & - & - \\
$\mathbf{O}=\mathbf{F}_{2}$ & - & - & - \\
Total & 100,17 & 100,17 & 100,00 \\
\hline \multicolumn{4}{r}{ Fonte: Webmineral, 2014. }
\end{tabular}

\subsubsection{ARGILAS DE ADSORÇÃO IÔNICA}

Os depósitos de argilas de adsorção iônica (AAI) portadores de TRs foram descritos pioneiramente em 1969 na província de Jinangxi (sul da China); desde então estão sendo descobertos e extraídos mais depósitos em todo o sul da China (Moldoveanu \& Papangelakis, 2013).

As AAl são uma importante fonte de TRs pesadas, mas apresentam teores de OTRs bastante baixos, entre 0,05 e 0,50\% (preferencialmente TRs pesadas), na forma de íons adsorvidos às camadas externas de filossilicatos, principalmente caulinita e haloisita, gerados pelo intemperismo de rochas magmáticas de origem primária, portadores de TRs (Chakmouradian \& Wall, 2012). Dessa forma, as TRs são adsorvidas na superfície dos minerais aluminosilicatados, como o caulim (Abrão, 1994).

Em comparação com minérios convencionais, como por exemplo, monazita e xenotima, as argilas possuem vantagens relacionadas à baixa radioatividade, bem como o processo de extração e beneficiamento simples. As argilas são derivadas do intemperismo laterítico de rochas contendo quantidades elevadas de TRs, onde durante este processo os íons $\mathrm{TR}^{3+}$ são mobilizados pela transferência para uma solução aquosa que percola através do corpo de intemperismo e são adsorvidos em superfícies minerais de argila (Voßenkaul et al., 2015).

Conforme descrito por Chi et al. (2005), devido à natureza das rochas hospedeiras, pH da água e do solo, temperatura, pressão, entre outras condições, existem três categorias principais de TRs presente nas AAI: 1) Fase coloidal: TRs depositadas como óxidos ou hidróxidos insolúveis ou como parte de coloidais que só podem ser recuperados por lixiviação ácida; 2) Fase Intercambiável: TRs ocorrem como cátions livres solúveis / cátions hidratados ou como parte de complexos carregados positivamente, representando $60-90 \%$ do teor total de TRs em minérios podendo ser recuperados por lixiviação por troca iônica com sais monovalentes; 3) Fase mineral: TRs são partículas finas sólidas com a mesma matriz de rede de cristal do minério, podendo ser recuperados somente por condições agressivas. 
Atualmente, as AAl são extraídas exclusivamente no sul da China e contribuem com uma grande quantidade, cerca de $80 \%$, para o suprimento global com as mais valiosas TRs pesadas (Voßenkaul et al., 2015).

\section{LIXIVIAÇÃO DE MINÉRIOS PORTADORES DE TERRAS RARAS}

O processo de lixiviação ácida é uma técnica que visa à solubilização de metais utilizando um ácido, que pode ser sob agitação constante e temperatura controlada. Durante o processo uma substância que se busca obter é extraída de uma matriz sólida através de sua dissolução por um agente lixiviante, que é escolhido seletivamente conforme a sua capacidade de dissolver o metal (Takahashi, 2008).

De acordo com Kim, et al. (2012) a monazita passa primeiramente por um beneficiamento físico, seguido do processamento químico, podendo ocorrer através do tratamento ácido utilizando ácido sulfúrico. O tratamento ácido da monazita depende de fatores como a razão ácido/minério, temperatura e da concentração do ácido. Conforme relatado por Santos e Ribeiro (2014), na decomposição da monazita por meio de baking ácido, onde pode ser utilizado ácido sulfúrico concentrado com temperatura entre $200-300^{\circ} \mathrm{C}$, por 2 horas. Seguido da lixiviação com água obtém-se os sulfatos solúveis de TRs, enquanto as demais espécies permanecem insolúveis. No entanto, algumas impurezas podem ser lixiviadas em conjunto, principalmente no caso de minérios de TRs que ocorrem juntamente com outras fases minerais contendo, como por exemplo, $\mathrm{Fe}, \mathrm{Al}$ e Th. Assim, antes do processo de extração por solventes para separação das TRs, alguma operação de purificação pode ser requerida como precipitação ou mesmo extração por solventes para remoção dos contaminantes presentes.

Ainda durante o processo de lixiviação, os fosfatos são dissolvidos na forma de ácido fosfórico, segundo as equações (1) e (2):

$$
\begin{aligned}
& 2 \mathrm{TR}_{2}\left(\mathrm{PO}_{4}\right)(\mathrm{s})+3 \mathrm{H}_{2} \mathrm{SO}_{4} \rightarrow 2 \mathrm{H}_{3} \mathrm{PO}_{4}(\mathrm{I})+\mathrm{TR}_{2}\left(\mathrm{SO}_{4}\right)_{3}(\mathrm{~s}) \\
& \mathrm{TR}_{2}\left(\mathrm{SO}_{4}\right)_{3}(\mathrm{~s})+\mathrm{H}_{2} \mathrm{O}(\mathrm{I}) \rightarrow \mathrm{TR}_{2}\left(\mathrm{SO}_{4}\right)_{3}(\mathrm{I})+\mathrm{H}_{2} \mathrm{O}(\mathrm{I})
\end{aligned}
$$

A bastnasita primeiramente passa pelo processamento físico, porém devido à sua natureza carbonatítica, muitas vezes é acompanhada de outros carbonatos como a calcita, aragonita (ambas como $\left.\mathrm{CaCO}_{3}\right)$, estroncianita $\left(\mathrm{SrCO}_{3}\right)$ ou dolomita $\left(\mathrm{Mg}, \mathrm{CaCO}_{3}\right)$, onde a dissolução de tais carbonatos é realizada através da lixiviação ácida com soluções de $\mathrm{HCl}$ concentrado e a altas temperaturas (Santos \& Ribeiro, 2014), segundo a equação (3):

$$
\mathrm{MCO}_{3}(\mathrm{~s})+2 \mathrm{HCl}(\mathrm{I}) \rightarrow \mathrm{MCl}_{2}(\mathrm{I})+\mathrm{H}_{2} \mathrm{O}(\mathrm{I})+\mathrm{CO}_{2} \text { 个 onde } \mathrm{M}=\mathrm{Ca} ; \mathrm{Sr}
$$


A lixiviação de AAl contendo TRs tem sido realizada usando soluções concentradas de sais inorgânicos de cátions monovalentes $\left(\mathrm{M}_{2} \mathrm{SO}_{4}\right.$ e $\mathrm{MCl}$, onde $\mathrm{M}=\mathrm{Na}^{+}$e $\left.\mathrm{NH}_{4}^{+}\right)$. Dessa forma, as TRs fisissorvidas podem ser dessorvidas e substituídas no substrato pelos íons monovalentes que são transferidos para solução na forma de sulfatos ou cloretos solúveis. As TRs solubilizadas são recuperadas e separadas como produtos finais de alta pureza, após as etapas de extração com solvente ou troca iônica (Santos \& Ribeiro, 2014).

\section{BIOLIXIVIAÇÃO DE MINÉRIOS PORTADORES DE TERRAS RARAS}

\subsection{Interações entre micro-organismos e minerais}

Na última década, vários estudos têm sido publicados abordando as interações entre micro-organismos e minerais portadores de TRs, incluindo a solubilização de TRs a partir de matrizes sólidas por meio de reações com metabólitos microbianos (Zhang et al., 2018) e a imobilização de TRs de matrizes líquidas, principalmente por sorção por biomassa (Coimbra, Nascimento \& Giese, 2017; Heidelmann et al., 2017; Coimbra et al., 2019; Giese, Barbosa-Dekker \& Dekker, 2019; Giese \& Jordão, 2019).

A mobilização de TRs mediada microbialmente ocorre principalmente via reações de acidólise, oxirredução e complexação. A acidólise, ou seja, a solubilização de íons metálicos induzida por prótons implica na troca e substituição de elementos metálicos a partir de superfícies minerais por prótons. A mobilização de TRs através de reações redutoras ou oxidativas, ou por ação de agentes complexantes produzidos metabolicamente também tem sido descrita na literatura.

No entanto, ainda são poucos os estudos que buscam elucidar qual a vantagem biológica da interação entre micro-organismos e minerais portadores de TRs. Estudos recentes demonstraram que alguns micro-organismos são estritamente dependentes de alguns elementos TRs os quais atuam como co-fatores essenciais para algumas de suas enzimas principais. Prejano et al. (2017), por exemplo, descreveram a importância dos íons $\mathrm{Ce}^{3+}$ no sítio ativo da enzima metanol desidrogenase produzida pela bactéria Methylacidiphilum fumariolicum.

Os micro-organismos são encontrados na natureza aderidos a superfícies sólidas, geralmente em rochas e minerais, através de um processo físico-químico resultante das propriedades hidrofílicas e/ou hidrofóbicas da superfície celular, sendo este dependente do $\mathrm{pH}$ e força iônica da solução em que se encontra, e também da superfície do suporte (Giese, 2014; Giese, 2019).

Durante o processo de adesão e fixação celular nos minerais, os micro-organismos produzem EPS (Extracellular Polymeric Substances), os quais são biopolímeros constituídos por polissacarídeos, proteínas, glicoproteínas, glicolipídios, que determinam as propriedades dos biofilmes, pois afetam diretamente a porosidade, densidade, atividade de água, hidrofobicidade, estabilidade mecânica dos mesmos, e principalmente, a carga e as propriedades de adesão (Harimawan \& Ting, 2016). 
Os biofilmes são embebidos em EPS e se desenvolvem em todas as interfaces óleo/água/mar, que são dessa forma denominados para se referir às comunidades microbianas que se encontram associadas à uma superfície. A formação de biofilmes é essencial para a sobrevivência da população bacteriana, formados através de uma sequência de eventos microbianos (Mikuta et al., 2012).Geralmente a superfície das partículas minerais apresentam excesso de carga negativa, o que torna-se necessário que os grupos aniônicos microbianos estejam complexados com constituintes catiônicos que confiram carga positiva ao biofilme para que ocorra a adesão celular sobre o mineral, independentes se provenientes de carga superfície celular ou dos EPS (Chen et al., 2013).

Desta maneira, o biofilme pode ser sorvido em superfícies minerais, alterando assim a capacidade do mineral de imobilizar metais pesados e outros elementos (Mikutta et al., 2012). Neste contexto, bactérias heterotróficas têm sido utilizadas na biolixiviação de minerais nãosulfetados, processo no qual os micro-organismos necessitam de uma fonte de energia orgânica e produzem diversos metabólitos secundários capazes de interagir com a superfície mineral e solubilizar os elementos metálicos. Dentre os metabólitos microbianos produzidos durante a lixiviação biológica com micro-organismos heterotróficos estão incluídos os EPS, ácidos orgânicos e sideróforos (Giese, 2014).

\subsection{Biolixiviação de terras raras: conceito e exemplos}

A biohidrometalurgia pode ser considerada uma tecnologia verde emergente para a recuperação de metais devido ao seu processamento ambiental amigável, simples e econômico. A biolixiviação consiste em um processo hidrometalúrgico de dissolução de minerais através da ação de um grupo de micro-organismos capazes de produzir ácidos e/ou agentes oxidantes a partir dos constituintes do próprio minério em processo de lixiviação (Giese, 2017; Giese, 2019). Alguns exemplos de estudos de biossolubilização de diferentes minerais portadores de TRs estão apresentados na Tabela 3. 
SOUZA, NASCIMENTO \& GIESE (2019)

HOLDS

Tabela 3: Exemplos de solubilização biológica de Terras Raras a partir de matrizes sólidas.

\begin{tabular}{|c|c|c|c|c|c|c|c|}
\hline Matriz & Terras Raras & Micro-organismo & $\begin{array}{l}\text { Fonte de } \\
\text { Carbono }\end{array}$ & $\begin{array}{c}\text { Agente lixiviante } \\
\text { (ácido) }\end{array}$ & $\begin{array}{c}\text { Tempo } \\
\text { (d) }\end{array}$ & $\begin{array}{c}\text { Temperatura } \\
(\stackrel{\circ}{ })\end{array}$ & $\begin{array}{c}\text { Taxa de } \\
\text { solubilização } \\
(\%) \\
\end{array}$ \\
\hline $\begin{array}{c}\text { Resíduos de escória } \\
\text { de cinzas }\end{array}$ & Sc, Y, La, Nd, Sm, Gd & Bactérias quimiolitotróficas & $\mathrm{CO}_{2}$ & Sulfúrico & 10 & 45 & $7-60$ \\
\hline $\begin{array}{l}\text { Folhelhos } \\
\text { carbonáceos }\end{array}$ & N.D. & $\begin{array}{l}\text { Fungos dos gêneros } \\
\text { Aspergillus e Penicillium }\end{array}$ & Sacarose & Cítrico e Oxálico & 7 & 30 & $11-86$ \\
\hline $\begin{array}{l}\text { Pó fosfórico de } \\
\text { lâmpadas } \\
\text { fluorescentes }\end{array}$ & Y & Bactérias quimiolitotróficas & $\mathrm{CO}_{2}$ & Sulfúrico & 16 & 30 & 70 \\
\hline Gibsita & N.D. & $\begin{array}{l}\text { Acidithiobacillus } \\
\text { ferrooxidans }\end{array}$ & $\mathrm{CO}_{2}$ & Sulfúrico & N.D. & 30 & 68 \\
\hline Monazita & $\mathrm{Ce}, \mathrm{La}, \mathrm{Nd}, \mathrm{Pr}$ & Aspergillus niger & $\begin{array}{l}\text { Açúcares e } \\
\text { amido }\end{array}$ & $\begin{array}{l}\text { Cítrico, glucônico, } \\
\text { oxálico e succínico }\end{array}$ & 6 & $25-28$ & $0,1-0,2$ \\
\hline Monazita & $\mathrm{Ce}, \mathrm{La}, \mathrm{Nd}, \mathrm{Pr}$ & Aspergillus terreus & $\begin{array}{l}\text { Açúcares e } \\
\text { amido }\end{array}$ & Itacônico e succínico & 6 & $25-28$ & $1,7-2,4$ \\
\hline Monazita & $\mathrm{Ce}, \mathrm{La}, \mathrm{Nd}, \mathrm{Pr}$ & Paecilomyces sp. & $\begin{array}{l}\text { Açúcares e } \\
\text { amido }\end{array}$ & $\begin{array}{l}\text { Acético, glucônico e } \\
\text { succínico }\end{array}$ & 6 & $25-28$ & $1,5-3,0$ \\
\hline Monazita & N.D. & Aspergillus ficuum & $\begin{array}{l}\text { Açúcares e } \\
\text { amido }\end{array}$ & Cítrico e oxálico & 9 & 30 & 75,4 \\
\hline Monazita & N.D. & Pseudomonas aeruginosa & $\begin{array}{l}\text { Açúcares e } \\
\text { amido }\end{array}$ & a-Cetoglucônico & 8 & 35 & 63,5 \\
\hline Fosfogesso & Y & Desulfovibrio desulfuricans & & & N.D. & 32 & 77 \\
\hline $\begin{array}{l}\text { Conglomerado de } \\
\text { quartzo }\end{array}$ & $\begin{array}{c}\mathrm{Y}, \mathrm{Ce}, \mathrm{Pr}, \mathrm{La}, \mathrm{Nd}, \mathrm{Yb}, \\
\text { Dy, Sa }\end{array}$ & Bactérias quimiolitotróficas & $\mathrm{CO}_{2}$ & Sulfúrico & 365 & N.D. & $16,3-76,1$ \\
\hline Lama vermelha & $\begin{array}{l}\mathrm{La}, \mathrm{Ce}, \mathrm{Pr}, \mathrm{Nd}, \mathrm{Sm} \\
\mathrm{Eu}, \mathrm{Gd}, \mathrm{Tb}, \mathrm{Dy}, \mathrm{Ho}, \\
\mathrm{Er}, \mathrm{Tm}, \mathrm{Yb}, \mathrm{Lu}, \mathrm{Y}, \mathrm{Sc}\end{array}$ & Penicillium tricolor & Sacarose & $\begin{array}{l}\text { Oxálico, cítrico e } \\
\text { glucônico }\end{array}$ & 50 & 30 & $36-78$ \\
\hline Solo & N.D. & Streptomyces sp. & Sacarose & N.D. & 2 & T. ambiente & $12-37$ \\
\hline $\begin{array}{l}\text { Concentrado de } \\
\text { Tório-Urânio }\end{array}$ & Y, La, Ce & Aspergillus ficuum & N.D. & Cítrico e oxálico & 1 & T. ambiente & $2,5-33$ \\
\hline $\begin{array}{l}\text { Concentrado de } \\
\text { Tório-Urânio }\end{array}$ & Y, La, Ce & Pseudomonas aeruginosa & N.D. & Sideróforos & 1 & 32 & $1,2-5,4$ \\
\hline Zircônia & $\mathrm{Y}, \mathrm{La}, \mathrm{Ce}, \mathrm{Pr}, \mathrm{Nd}, \mathrm{Sm}$ & Acidithiobacillus sp. & $\mathrm{CO}_{2}$ & Sulfúrico & 10 & 32 & 79,6 \\
\hline
\end{tabular}

HOLOS, Ano 35, v.1, e8274, 2019 


\begin{tabular}{|c|c|c|c|c|c|c|c|}
\hline & $\begin{array}{c}\text { Eu, Gd, Tb, Dy, Ho, } \\
\text { Er, Tm, Yb, Lu }\end{array}$ & & & & & & \\
\hline Zircônia & $\begin{array}{c}\text { Y, La, Ce, Pr, Nd, Sm, } \\
\text { Eu, Gd, Tb, Dy, Ho, } \\
\text { Er, Tm, Yb, Lu }\end{array}$ & Acetobacter methanolicus & Glucose & Glucônico & 10 & 32 & 67,0 \\
\hline Zircônia & $\begin{array}{c}\text { Y, La, Ce, Pr, Nd, Sm, } \\
\text { Eu, Gd, Tb, Dy, Ho, } \\
\text { Er, Tm, Yb, Lu }\end{array}$ & $\begin{array}{l}\text { Acidithiobacillus } \\
\text { ferrooxidans }\end{array}$ & $\mathrm{CO}_{2}$ & Sulfúrico & 10 & 32 & $45-92$ \\
\hline Zircônia & $\begin{array}{c}\text { Y, La, Ce, Pr, Nd, Sm, } \\
\text { Eu, Gd, Tb, Dy, Ho, } \\
\text { Er, Tm, Yb, Lu }\end{array}$ & Acetobacter methanolicus & Glucose & Glucônico & 10 & 32 & $59-89$ \\
\hline
\end{tabular}

N.D. = não determinado

Fonte: Helmut et al., 2016 
Essa rota alternativa para a recuperação de TRs pode apresentar vantagens como a economia de insumos (ácidos e agentes oxidantes), visto que os micro-organismos produzem tais insumos como metabólitos secundários a partir dos constituintes do minério. $O$ processo biohidrometalúrgico apresenta ainda menor requerimento energético, baixo investimento de capital inicial e menor custo operacional (Yamane, 2012).

Os micro-organismos apresentam um papel importante na biolixiviação de TRs através da produção de ácidos orgânicos. Bactérias quimiolitotróficas como Acidithiobacillus ferrooxidans foram descritas por degradarem a zircônia através da produção de ácido glucônico (Pollman et al., 2016), enquanto bactérias heterotróficas tais como Acetobacter sp. e Pseudomonas aeroginosa foram capazes de biolixiviar TRs a partir de monazitas (Hassanien et al., 2014; Shin et al., 2015; Pollman et al., 2016).

No estudo realizado por Hassanien et al., (2014), durante o processo de lixiviação direta, o $\mathrm{pH}$ do liquor diminuiu durante o crescimento das bactérias $A$. ficcum e $P$. aeruginosa devido à produção de ácidos orgânicos e aminoácidos, entre outros. Esses metabólitos podem dissolver os minerais através do deslocamento de íons metálicos da superfície de minerais sólidos por íons de hidrogênio ou pela formação de complexos metálicos solúveis e quelatos.

No processo de biolixiviação indireta, os pesquisadores observaram que o pH do meio reacional aumentou em apensas $24 \mathrm{~h}$, devido ao consumo de prótons ao converter os óxidos metálicos presentes em sais metálicos solúveis. Em conclusão, durantes os estudos de crescimento de A. ficcum e P. aeruginosa, os substratos minerais, formados por amostras de monazita, sofreram ação dos ácidos cítrico, oxálico, tartárico e gluconônico produzidos biologicamente, que desempenharam um papel fundamental na mobilidade ambiental dos íons metálicos.

O estudo realizado por Brisson et al. (2015), utilizando uma amostra de monazita e três espécies de fungos (Aspergillus niger, Aspergillus terreus e Paecilomyces sp.), foi conduzido na presença de diferentes ácidos orgânicos (acético, cítrico, glucônico, itacônico, lático, oxálico e succínico). As taxas de lixiviação de TRs foram de aproximadamente 3\%, e consideradas bastante baixas. Em comparação com a composição inicial de TRs da monazita avaliada, concluiu-se que neodímio, cério, praseodímio e lantânio foram mobilizados pelas três linhagens fúngicas na mesma proporção, não sendo observada nenhuma preferência de biolixiviação de um elemento de TRs em particular.

Com a finalidade de investigar se o processo de biolixiviação de TRs na monazita ocorria devido às características químicas do material sólido ou devido às preferências metabólicas dos micro-organismos utilizados, Desouky et al. (2011) realizaram um experimento de biolixiviação utilizando duas cepas bacterianas, de Aspergillus ficcum e de Pseudomonas aeruginosa. Cerca de 53\% de TRs foram liberados para o meio de cultivo na presença de $P$. aeruginosa, enquanto $A$. ficcum conseguiu mobilizar aproximadamente 75\% e TRs, após 9 dias de biolixiviação com uma densidade de polpa de $6 \mathrm{~g} / \mathrm{L}$. Neste estudo foi possível comprovar que a biolixiviação de contato, ou seja, com o meio reacional composto por bactérias e mineral em contato, resultou em taxas maiores de lixiviação, indicando que a presença de micro-organismos é necessária para a obtenção de maiores teores de TRs. Em outro estudo, Hassanien et al. (2014) relataram que as mesmas bactérias, A. ficcum e P. aeruginosa, liberaram até $60,6 \%$ e $52,6 \%$ de TRs totais da monazita, respectivamente. Neste experimento foi possível demonstrar o efeito de diferentes 
concentrações de monazita no crescimento, produção de ácidos e comportamento de lixiviação das bactérias avaliadas.

Para as AAl, a biolixiviação é proposta como uma alternativa sustentável às técnicas convencionais, onde micro-organismos tais como Aspergillus niger e Bacillus sp. podem ser utilizados. Barnett et al. (2017) avaliaram o potencial da biolixiviação para a recuperação de TRs a partir de AAI. Ao longo de 60 dias, cerca de $80 \%$ de TRs foram extraídos na presença de sulfato de amônio. A exceção foi o elemento cério, onde a maior quantidade lixiviada foi observada na presença do fungo Aspergillus niger em apenas 3 dias de lixiviação.

Com o objetivo de analisar o processo de biolixiviação de TRs em uma amostra de bastnasita, Zhang et al. (2018) utilizaram quatro cepas de actinobactérias, sendo duas isoladas de uma mina rica em TRs na China e duas isoladas do solo vermelho ao redor da mina. Os resultados mostram que estas actinobactérias têm capacidade de biolixiviação de TRs, porém apresentam eficiência e mecanismos de ação diferenciados. A concentração total de TRs variou de 56 a 342 $\mu \mathrm{g} / \mathrm{L}$ em um meio de crescimento rico em nutrientes, porém, em meio oligotrófico, apenas uma cepa (Streptomyces sp.) cresceu na presença da bastnaesita e foi capaz de lixiviar até $548 \mu \mathrm{g} / \mathrm{L}$ de TRs totais.

Taxas maiores de solubilização de TRs podem ser obtidas através da biolixiviação de minerais e resíduos com baixos teores destes elementos. Dudeney \& Sbai (1993) avaliaram a biolixiviação de fosfogesso por Desulfovibrio desulfuricans, bactérias redutoras de sulfato, e obtiveram eficiência de quase $80 \%$ utilizando um reator de leito fixo. Ibrahim \& El-Sheikh (2011) utilizaram a bactéria Acidithiobacillus ferrooxidans visando a solubilização biológica de uma amostra de gibsita proveniente do sudoeste do Sinai (Egito). O minério testado apresentava uma concentração de $4,9 \mathrm{~g}$ de TRs por $\mathrm{kg}$, sendo que as taxas de recuperação alcançadas foram de aproximadamente $67,6 \%$ em um processo de biolixiviação em colunas (1,2 m de altura) contendo $1 \mathrm{~kg}$ da amostra mineral, resultando na solubilização de 3,3 g de TRs por kg. Por fim, Amin et al. (2014) obtiveram eficiências de lixiviação de TRs de $86 \%$ a partir do pó de xisto carbonado com o uso de espécies fúngicas de Aspergillus e Penicillium.

Além dos ácidos produzidos biologicamente, outras moléculas quelantes também podem ser importantes para a solubilização de TRs. Por exemplo, descobriram-se que alguns sideróforos tem o poder de quelar os elementos TRs. Os sideróforos são moléculas orgânicas de baixo peso molecular produzidas por muitas bactérias e fungos e até mesmo plantas, em ambientes deficientes em ferro para solubilizar ferro pouco solúvel (Christenson \& Schijf, 2011). No entanto, os sideróforos também complexam uma série de outros íons metálicos polivalentes. Em experimentos de lixiviação numa variedade de rochas ígneas, Kraemer et al., (2015) observaram um aumento na solubilidade de TRs em soluções contendo o sideróforo de hidroxamato desferroxamina $B$ em comparação às obtidas em água ultrapura e soluções de ácidos clorídrico e acético.

\section{CONSIDERAÇÕES FINAIS}

Métodos hidrometalúrgicos baseados no emprego de processos biotecnológicos para a extração e recuperação de metais podem ser considerados uma alternativa complementar às 
técnicas hidrometalúrgicas convencionais para recuperação e reciclagem de TRs. Uma grande variedade de grupos microbianos, fisiologicamente distintos, apresentam potencial para serem aplicados à matrizes sólidas em diferentes processos de biolixiviação. Dependendo da matriz mineral, do micro-organismo, e do elemento-alvo, podem ser obtidas eficiências de lixiviação de 80 a $90 \%$. A biotecnologia aliada à cadeia produtiva de elementos de TRs pode ajudar a reduzir o risco de fornecimento destes metais e a dependência do mercado. Adicionalmente, a aplicação de técnicas de biolixiviação para o tratamento de resíduos sólidos pode contribuir para uma economia mais sustentável e ecologicamente correta.

\section{AGRADECIMENTOS}

A primeira autora agradece ao CNPq pela bolsa PIBIC (CETEM/MCTIC) concedida. Agradecemos às professoras Dra. Helga Stefania Maranhão Bodstein e Dra. Flávia Alexandra Gomes de Souza pelas valiosas sugestões e comentários.

\section{REFERÊNCIAS}

Abrão, A. (1994). Química e tecnologia das terras-raras. Rio de Janeiro: CETEM/MCTIC.

Amin, M. M., Ei-Assy, I. E., El-Feky, M. G., Sallam, A. M., El-Sayed, E. M., Nada, A. A., \& Harpy, N. M. (2014) Fungal leaching of rare earth elements from lower carboniferous shales, southwestern Sinai, Egypt. Romanian Journal of Biophysics, 24(1), 25-41.

Antoniassi, J. L. (2017). Caracterização tecnológica de recursos minerais de Terras Raras em complexos alcalinos e alcalino-carbonatíticos do Brasil. Tese de doutorado, Universidade de São Paulo, São Paulo, SP, Brasil.

Barmettler, F., Castelberg, C., Fabbri, C., \& Brandl, H. (2016) Microbial mobilization of rare earth elements (REE) from mineral solids - A mini review. AIMS Microbiology, 3(2), 190-204. DOI:10.3934/microbiol.2016.2.190

Barnett, M., Gregory, S., \& Palumbo-Roe, B. (2017, maio). Assessment of bioleach and salt leach for the extraction of rare earth elements from ion adsorption clays. Anais do 2nd European Rare Earth Resources Conference, Santorini, Grecia, 106-108.

Brisson, V. L., Zhuang, W. Q., \& Alvarez-Cohen, L. (2015) Bioleaching of rare earths elements from monazite sands. Biotechnology and Bioengineering, 113(2), 339-348. DOI:10.1002/bit.25823

Castor, S. B., \& Hedrick, J. B. (2006). Rare Earth Elements. (Cap. 5, pp.769-792). USA: Society for Mining, Metallurgy and Exploration.

Chakmouradian, A. R., \& Wall, F. (2012) Rare elements: Minerals, Mines, Magnets (and More). Elements, 8(5), 333-340. DOI:10.2113/gselements.8.5.333

Chen, Y-P., Zhang, P., Guo, J-S., Fang, F., Gao, X., \& Li, C. (2013) Functional groups characteristics of EPS in biofilm growing on different carriers. Chemosphere, 92(1), 633-638. DOI:10.1016/j.chemosphere.2013.01.059 
Chi, R., Tian, J., Li, Z., Peng, C., Wu, Y., Li, S., Wang, C., \& Zhou, Z. (2005) Existing state and partitioning of rare earth on weathered ores. Journal of Rare Earths, 23(6), 756-759.

Christenson, E. A., \& Schijf, J. (2011) Stability of YREE complexes with the trihydroxamate siderophore desferrioxamine B at seawater ionic strength. Geochimica at Cosmochimica Acta, 75(22), 7047-7062. DOI:10.1016/j.gca.2011.09.022

Coimbra, N. V., Nascimento, M., \& Giese, E. C. (2017) Avaliação do uso de biomassa bacteriana imobilizada na biossorção de terras-raras leves e médias. HOLOS, 6(1), 136-146. DOI:10.15628/holos.2017.6445

Coimbra, N. V., Gonçalves, F. S., Nascimento, M., \& Giese, E. C. (2019) Study of adsorption isotherm models on rare earth elements biosorption for separation purposes. International Scholarly and Scientific Research \& Innovation, 13(1), 86-86.

Desouky, O. A., El-Mougith, A. A., Hassanien, W. A., Awadalla, G. S., \& Hussien, S. S. (2016) Extraction of some strategic elements from thorium-uranium concentrate using bioproducts of Aspergillus ficuum and Pseudomonas aeruginosa. Arabian Journal of Chemistry, 9(1), S795-S805. DOI:10.1016/j.arabjc.2011.08.010

Departamento Nacional de Produção Mineral (DNPM). (2014). Sumário Mineral. Recuperado em 15 março, 2018, de http://www.dnpm.gov.br/dnpm/sumarios/sumario-mineral-2014

Dudeney, A. W. L., \& Sbai, M. L. (1993) Bioleaching of rare-earth-bearing phosphogypsum. (Cap. 2, pp. 39-47). USA: The Minerals, Metals, \& Materials Society.

Giese, E. C. (2014). Biofilmes: a interação micro-organismo/substrato mineral na biolixiviação. Rio de Janeiro: CETEM/MCTIC.

Giese, E. C. (2017). Biolixiviação: Uma avaliação das inovações tecnológicas na biomineração de minerais sulfetados no período de 1991 a 2015. Tecnologia em Metalurgia, Materiais e Mineração, 14(3), 192-203. DOI:10.4322/2176-1523.1205

Giese, E. C. (2017). Tendências européias para o uso dos recursos de terras-raras. Rio de Janeiro: CETEM/MCTIC.

Giese, E. C., Barbosa-Dekker, A. M., \& Dekker, R. F. H. (2019) Biosorption of lanthanum and samarium by viable and autoclaved mycelium of Botryosphaeria rhodina MAMB-05. Biotechnology Progress, p. e2783. DOI:10.1002/btpr.2783

Giese, E. C. (2019) Evidences of EPS-iron (III) ions interactions on bioleaching process mini-review: the key to improve performance. ORBITAL: THE ELECTRONIC JOURNAL OF CHEMISTRY, 11(1), 200-204.

Giese, E. C., \& Jordão, C. S. (2019) Biosorption of lanthanum and samarium by chemically modified Bacillus subtilis free cells. Applied Water Science, 9(1), p. 182. DOI:10.1007/s13201-019-1052-3

Gupta, C. K., \& Krishnamurthy, N. (2005). Extrative Metallurgy of Rare Earths. Boca Raton: CRC Press.

Haque, N., Hughes, A., Lim, S., \& Vernon, C. (2014) Rare earth elements: overview of mining, mineralogy, uses, sustainability and environmental impact. Resources, 3(4), 614-635. DOI:10.3390/resources3040614 
Harimawan, A. \& Ting, Y. P. (2016) Investigation of extracellular polymeric substances (EPS) properties of $P$. aeruginosa and $B$. subtilis and their role in bacterial adhesion. Colloids and Surfaces B: Biointerfaces, 146(1), 459-467. DOI:10.1016/j.colsurfb.2016.06.039

Hassanien, W. A., Desouky, O. A., \& Hussien, S. S. (2014) Bioleaching of some rare earth elements from Egyptian monazite using Aspergillus ficuum and Pseudomonas aeruginosa. Journal of Science and Technology (WJST), 11(9), 809-823. DOI:10.14456/WJST.2014.85

Heidelmann, G. P., Roldão, T. M., Egler, S. G., Nascimento, M., \& Giese, E. C. (2017) Uso de biomassa de microalga para biossorção de lantanídeos. HOLOS, 6(1), 170-179. DOI:10.15628/holos.2017.6436

Heider, M. (2018). A evolução das Terras Raras no Brasil. Recuperado em 01 agosto, 2018, de https://inthemine.com.br/site/a-evolucao-das-terras-raras-no-brasil/

Ibrahim, H. A., \& El-Sheikh, E. M. (2011) Bioleaching treatment of Abu Zeneima Uraniferous gibbsite ore material for recovering $U$, REEs, Al and Zn. Research Journal of Chemical Sciences, 1(14), 55-66.

Jones, A. P., Wall, F., \& Williams, C. T. (1996) Rare Earth minerals: chemistry, origin and ore deposits. London: Chapman \& Hall.

Kim, E., \& Osseo-Asare, K. (2012) Aqueous stability of thorium and rare earth metals in monazite hydrometallurgy: Eh-pH diagrams for the systems Th-, Ce-, La-, $\mathrm{Nd}-\left(\mathrm{PO}_{4}\right)-\left(\mathrm{SO}_{4}\right)-\mathrm{H}_{2} \mathrm{O}$ at $25^{\circ} \mathrm{C}$. Hydrometallurgy, 113-114(1), 67-78. DOI:10.1016/j.hydromet.2011.12.007

Kraemer, D., Kopf, S., \& Bau, M. (2015) Oxidative mobilization of cerium and uranium and enhanced release of "immobile" high field strength elements from igneous rocks in the presence of the biogenic siderophore desferrioxamine B. Geochimica et Cosmochimica Acta, 165(1), 263-279. DOI:10.1016/j.gca.2015.05.046

Lapido-Loureiro, F. E., \& Santos, R. L. C. (2013). O Brasil e a reglobalização da indústria das Terras Raras. Rio de Janeiro: CETEM/MCTIC.

Loureiro, F. E. L. (1994). Terras raras no Brasil: depósitos, recursos identificados, reservas. Rio de Janeiro: CETEM/MCTIC.

Loureiro, F. E. L., \& Santos, L. C. (2013). Terras raras: do monopólio da produção primária ao oligopólio tecnológico. Brasil e a reglobalização da indústria das Terras Raras. Rio de Janeiro: CETEM/MCTIC.

Mariano, A. N. (1989). Nature of economic mineralization in carbonatites and related rocks. (Cap. 5, pp. 149-176). London: Unwin Hyman Ltd.

Martins, T. S., \& Isolani, P. C. (2005) Terras raras: aplicações industriais e biológicas. Química Nova, 28(1), 111-117. DOI:10.1590/S0100-40422005000100020

Mclellan, B. C., Corder, G. D., Golev, A., \& Ali, S. H. (2014) Sustainability of the Rare Earths $\begin{array}{llll}\text { industry. Procedia } \quad \text { Environmental 20(1), } & \text { 280-287. }\end{array}$ DOI:10.1016/j.proenv.2014.03.035

Mikutta, R., Baumgartner, A., Schippers, A., Haumaier, L., \& Guggenberger, G. (2012) Extracellular polymeric substances from Bacillus subtilis associated with minerals modify the extent and rate of heavy metal sorption. Environmental, Science and Technology, 46(7), 3866-3873. DOI:10.1021/es204471x 
Moldoveanu, G. A., \& Papangelakis, V. G. (2013) Recovery of Rare Earth Elements absorbed on clay minerals: II. Leaching with ammonium sulfate. Hydrometallurgy, 131-132(1), 158-166. DOI:10.1016/j.hydromet.2012.10.011

Pollmann, K., Kutschke, S., Matys, S., Kostudis, S., Hopfe, S., \& Raff, J. (2016) Novel biotechnological approaches for the recovery of metals from primary and secondary resources. Minerals, 6(2), 1-13. DOI:10.3390/min6020054

Prejanò, M., Marino, T., \& Russo, N. (2017) How can methanol dehydrogenase from Methylacidiphilum fumariolicum work with the Alien $\mathrm{Ce}(\mathrm{III})$ in the active center? A theoretical study. Chemistry, 22-23(36), 8652-8657. DOI:10.1002/chem.201700381

Ramalho, T. E. B, Vital, A. B, Moriyama, A. L. L., \& Souza, C. P. (2016, outubro) Caracterização do mineral monazita/alanita proveniente do estado de Goiás. Anais do Congresso Brasileiro de Engenharia Química, Fortaleza, CE, Brasil, 40757.

Rosental, S. (2005). Terras raras. (Cap. 30, pp. 629-654). Rio de Janeiro: CETEM/MCTIC.

Santos, R. L. C., \& Ribeiro, V. M. (2014). Breve revisão bibliográfica dos processos de lixiviação de minérios e concentrados de terras-raras. Rio de Janeiro: CETEM/MCTIC.

Senado Federal, Secretaria Especial de Comunicação Social. (2013). Terras Raras: Estratégia para o futuro. Em discussão, 4(17), 62.

Serra, O. A., Lima, J. F., \& De Sousa Filho, P. C. (2015) A Luz e as Terras Raras. Revista Virtual de Química, 7(1), 242-264. DOI:10.5935/1984-6835.20150012

Shin, D., Kim, J., Kim, B., Jeong, J.,\& Lee, J. C. (2015) Use of phosphate solubilizing bacteria to leach rare earth elements from monazite-bearing ore. Minerals, 5(2), 189-202. DOI:10.3390/min5020189

Sousa Filho, P. C., \& Serra, O. A. (2014) Terras raras no Brasil: histórico, produção e perspectivas. Química Nova, 37(4), 753-760. DOI:10.5935/0100-4042.20140121

Takahashi, V. C. I. (2008). Reciclagem de baterias de íons de Li: condicionamento físico e extração do Co. Dissertação de mestrado, Universidade de São Paulo, São Paulo, SP, Brasil.

Termo de Compromisso de Gestão (TCG) (2013). Recuperado em 18 maio, 2018, de http://www.cetem.gov.br/images/gestao/tcg_2013.pdf. Acessado em: 18 mai 2018.

U.S. Department of Energy: Critical Materials Strategy (2017). Recuperado em 01 agosto, 2017, de https://www.energy.gov/sites/prod/files/piprod/documents/cms_dec_17_full_web.pdf.

USEPA (2012). Rare earth elements: A review of production, processing, recycling, and associated environmental issues, EPA/600/R-12/572, USEPA: Cincinnati.

Vera, Y. M. (2015). Separação de Terras Raras a partir da extração por solvente: revisão sobre o uso dos extratantes ácidos organofosforados. Rio de Janeiro: CETEM/MCTIC.

Viera, E. V., \& Lins, F. A. F. (1997). Concentração de minérios de terras-raras: uma revisão. Rio de Janeiro: CETEM/MCTIC.

Voßenkaul, D., Stoltz, N. B., Meyer, F. M., \& Friedrich, B. (2015) Extraction of rare earth elements from non-Chinese ion adsorption clays. Proceedings of European Metallurgical Conference (EMC), 703-715. Düsseldorf, Germany: GDMB. 
Voncken, J. H. L. (2016). The ore minerals and major ore deposits of the Rare Earths. (Cap 1., pp. 15-52) USA: Springer International Publishing.

Wu, S., Zhang, L., Wang, L., Zhao, L., Zhang, P., El-Shall, H., Moudgilc, R., \& Huanga, X. (2018) Recovery of rare earth elements from phosphate rock by hydrometallurgical processes - A critical review. Chemical Engineering Journal, 335, 774-800. DOI:10.1016/j.cej.2017.10.143

Yamane, L. H. (2012). Recuperação de metais de placas de circuito impresso de computadores obsoletos através de processo biohidrometalúrgico. Tese de doutorado, Universidade de São Paulo, São Paulo, SP, Brasil.

Zhang, Z., Jia, Q., \& Liao, W. (2015). Progress in the separation processes for Rare Earth resources. (Cap. 4, pp. 287-376) North Holland: Elsevier Inc.

Zhang, L., Dong, H., Yan, L., Bian, L., Wang, X., Zhou, Z.,\& Huang, Y. (2018) Bioleaching of rare earth elements from bastnaesite-bearing rock by actinobacteria. Chemical Geology, 483, 544-557. DOI:10.1016/j.chemgeo.2018.03.023

Zhou, B., Li, Z., \& Chen, C. (2017) Global potential of rare earth resources and rare earth demand from clean technologies. Minerals, 7(11), 203-217.

Zini, J. (2010). Usos das cromatografias de extração e de troca iônica na separação de tório e Terras Raras de um resíduo gerado na unidade de purificação de tório. Aplicação das Terras Raras como catalisadores na geração de hidrogênio. Tese de doutorado, Universidade de São Paulo, São Paulo, SP, Brasil. 